\title{
The Formation Mechanism and Precision Control of Corruption in Poverty Alleviation from the Perspective of System Dynamics
}

\author{
Yan Zheng $\mathbb{B D}^{1}$ and Xiaoming Liao $\mathbb{D D}^{2}$ \\ ${ }^{1}$ School of Management, Nanchang University, Nanchang Jiangxi, 330031, China \\ ${ }^{2}$ School of Public Administration, Nanchang University, Nanchang Jiangxi, 330031, China \\ Correspondence should be addressed to Xiaoming Liao; liaoxiaominggong@163.com
}

Received 29 August 2018; Accepted 8 October 2018; Published 17 October 2018

Academic Editor: Sabri Arik

Copyright (c) 2018 Yan Zheng and Xiaoming Liao. This is an open access article distributed under the Creative Commons Attribution License, which permits unrestricted use, distribution, and reproduction in any medium, provided the original work is properly cited.

\begin{abstract}
The corruption in the field of poverty alleviation not only hinders the performance of the government but also damages the vital interests of the poor, harms the image of the party and the country, and makes the poor people further impoverished. Based on the method of system dynamics, this paper analyzes the interaction of elements which influence village officials' corruption, studies the formation mechanism of the corruption in poverty alleviation, and constructs an effective model to prevent the corruption. Based on the survey data of typical cases, the model was simulated and validated by the software of Vensim PLE. The study found that compared with other variables, the willingness of village officials to corrupt has the greatest impact on the amount of their corruption. Furthermore, it is found that the important factors that affect village officials' corruption willingness are as in the following order: official culture, village officials' thought, and prevention system.
\end{abstract}

\section{Introduction}

Poverty alleviation is one of the three major affairs put forward by the 19th National Congress of the Communist Party of China. In February 2018, President Xi Jinping pointed out at the Symposium on Precise Poverty Alleviation that "formalism, bureaucracy, falsification, impatience and boredom and negative corruption in poverty alleviation work still exist, and some are still very serious" [1]. The No. 1 Document of the Central Committee in 2018 pointed out that it is necessary to "make a good fight against poverty and strengthen the struggle in order to let the poor to gain a sense of support" and to "strengthen the responsibility and supervision of poverty alleviation ... to carry out special governance on corruption in the process of poverty alleviation" [2].

Chinese scholars have conducted the following research on corruption in the field of poverty alleviation. He [3] believes that the main reason for the phenomenon of "poverty alleviated" and "fake poverty alleviation" in the field of precision poverty alleviation is the information asymmetry between poor households and officials. Shen [4] examined 168 typical cases in the six provinces of central China and believed that the weakening of the supervision of grassroots village cadres, the opacity of village affairs in the precision poverty alleviation project, unsoundness of the village cadre salary guarantee mechanism, and the limited binding laws and regulations are the main causes of corruption in the field of precision poverty alleviation. Ma [5] believes that the main problems in China's rural poverty alleviation are related to the misunderstanding of human nature, the quality of the poor themselves, and the backwardness of the poverty alleviation system. Chen and $\mathrm{Hu}[6]$ believe that the "small micro-"corruption in the rural grassroots is related to the psychological factors of the village officials and the external environment. Mo [7] believes that reducing corruption in the poverty alleviation needs to strengthen the supervision of the village officials. Wang [8] believes that reducing the duty crimes in the field of poverty alleviation needs to improve the punishment mechanism for grassroots cadres.

The existing literature uses game theory, cases analysis, and logical reasoning to analyze the corruption in the field of precision poverty alleviation and put forward effective suggestions. Just as scholars have found, the cause of corruption in the field of precision poverty alleviation is not the 
single factor, but the result of multiple factors. Then, among the factors affecting corruption in the poverty alleviation, which factor has a major impact on the corruption? Are these influencing factors also interact with each other? In order to answer these questions, this paper regards corruption in the field of precision poverty alleviation as a complete system and uses the method of system dynamics to analyze those questions. We build a model to prevent village officials' corruption based on qualitative analysis because system dynamics can better analyze and solve complex problems within causality in social systems [9-11]. Later, combined with typical cases and survey data in the field of precision poverty alleviation, the model was simulated and tested.

\section{Causality Analysis}

The causes of corruption are not only related to ideology and culture [12] but also related to government policies [13-16], media reports $[17,18]$ and reports by people [19].

2.1. Village Officials Subsystem. Existing literature shows that corruption is related to public officials' thought, opportunities, and social environment. The same is true for village officials who are in the field of precision poverty alleviation. First of all, as the level of grassroots village officials' thought is influenced by the selection conditions and the education of the coming days, their political literacy is generally not high, leaving a large space for the village officials to corruption. Secondly, influenced by the herd mentality, the official culture has an impact on village officials' corruption. When the official culture is clean, the village officials have a lower willingness to corruption. On the contrary, when the official culture is not clean enough, the village officials have a higher willingness to corruption. Thirdly, the factor of prevention system plays a role on village officials' corruption. The more sound the poverty alleviation system, the higher the cost of corruption for village officials and the lower the willingness of village officials to corrupt. In the village officials' subsystem, the village officials' thought, official culture, and prevention system are selected as relevant variables to study their influence on the village officials' willingness to corruption. When the ideology of village officials is lower, the official culture is less clean and the prevention system is not sounder, the village officials' willingness to corrupt is higher, and the amount of village officials' corruption is more. And the willingness of village officials to corrupt is positively related to the amount of village officials' corruption, which constitutes a positive feedback loop.

2.2. People Subsystem. The amount of corruption convicted by village officials is affected by the amount of corruption reported by people. And the amount of corruption reported by people is reflected by the willingness of people to report. The willingness of people to report is related by the ability people to report, the way to report, and the satisfaction with the results of the report. These three elements constitute the key variables of the reporting subsystem of people, and the relationship between the three is a multiplicative relationship.
In other words, if one of the three elements is 0 , the action of people's report will not be realized. The higher the willingness of people to report corruption, the less the willingness of public officials to corrupt. Therefore, the people's willingness to report is negatively related to the amount of corruption, which constitutes a closed negative feedback loop.

2.3. Government Subsystem. The amount of corruption convicted by village officials is affected by the number of corruption investigated by government. And the number of corruption investigated by government is related to the awareness of investigating corruption and the technical means of investigating corruption. As the awareness of investigating corruption and the technical means of investigating corruption can improve the ability of government's investigating corruption. And the sound ability of government investigate corruption can reduce the willingness of village officials' corruption. On the one hand, the increase in the number of village officials' corruption has forced the government to improve its ability to investigate corruption. On the other hand, the stronger the government's awareness of investigating corruption and the more advanced technical means of investigating corruption, the more the government investigates corruption and the less the village officials' corruption. In the government subsystem, the government's awareness of investigating corruption and the ability to investigate are negatively related to the corruption of village officials, forming a closed negative feedback loop.

2.4. Media Subsystem. Firstly, the willingness of media report corruption is related to the degree of media's competition. The higher the level of media's competition, the more transparent the information and the less the village officials dare to corrupt. Secondly, the media's willingness to report corruption is related to the number of corruption convicted by village officials and the number of corruption reported by people and the number of corruption investigated by government. The more the village officials convict corruption, the more the people report corruption, the more the government investigates corruption, and the more the media report corruption. The more the media reported corruption, the less the village officials dare to corrupt. Therefore, in the media subsystem, the amount of corruption reported by the media is negatively correlated with the amount of corruption convicted by village officials, which constitutes a closed negative feedback loop.

2.5. Interaction of Variables. In the prevention corruption model of precision poverty alleviation, the variables are interacted each other. On the one hand, the more the number of corruption reported by people, investigated by government, reported by media, the less the village officials want to corrupt, which constitutes a negative feedback loop. On the other hand, the more the village officials want to corrupt, the more the number of corruption convicted by village officials, which constitutes a positive feedback loop. Therefore, the entire system constitutes a growth ceiling model for village officials' corruption (see Figure 1). 


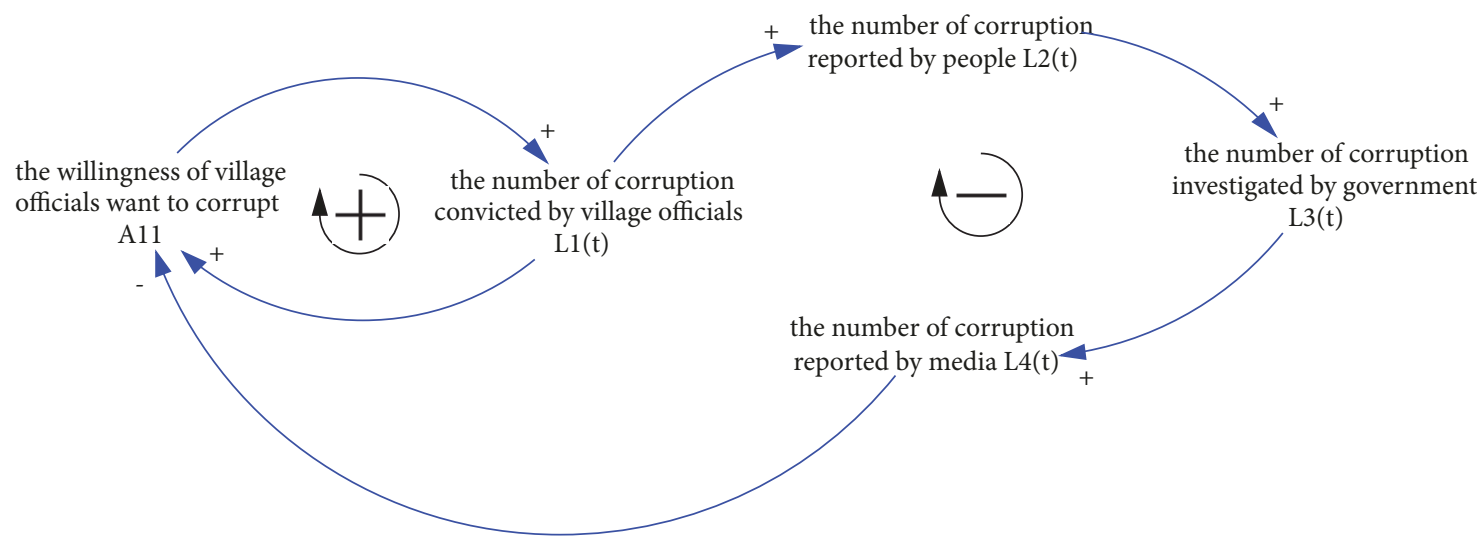

FIGURE 1: The complete causal loop of the system.

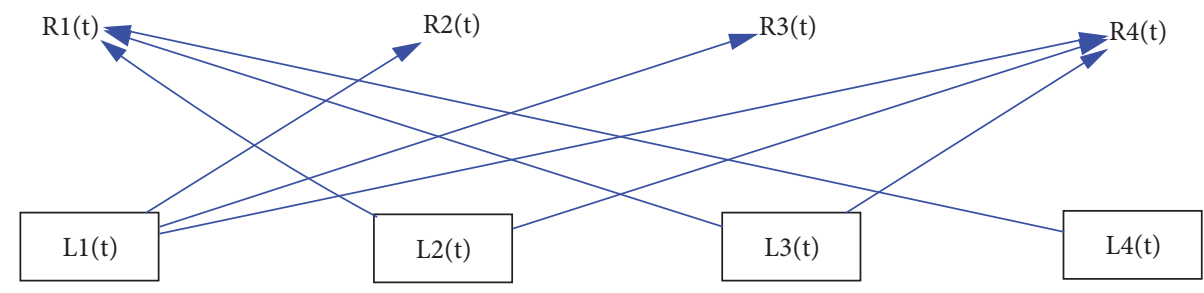

FIGURE 2: The two-part diagram of rate variable based in-tree model of the village official corruption.

\section{The Boundary and Model of the System}

3.1. The Boundary of the System. By analyzing and controlling the information flow of multilevel and complex structures in the system, system dynamics can better solve the dynamic complex feedback problem of social systems [11]. Based on the research purpose and qualitative analysis of this paper, the boundary of the village officials corruption prevention system in the field of precision poverty alleviation is obtained: the number of corruption convicted by village officials and its changes; the number of corruption reported by people and its changes; the number of corruption investigated by government and its changes; the number of corruption reported by media and its changes. This model does not consider the impact of other factors on village officials' corruption:

(1) the number of corruption convicted by village officials $\mathrm{L}_{1(\mathrm{t})}$ and its changes $R_{1(t)}$

(2) the number of corruption reported by people $\mathrm{L}_{2(\mathrm{t})}$ and its changes $R_{2(t)}$

(3) the number of corruption investigated by government $\mathrm{L}_{3(\mathrm{t})}$ and its changes $R_{3(t)}$

(4) the number of corruption reported by media $\mathrm{L}_{4(\mathrm{t})}$ and its changes $R_{4(t)}$.

3.2. The Model of the System. The rate variable based in-tree model and the flow graph model are two common models for system dynamics. The flow graph model is not standardized while constructing a model. The rate variable based in-tree model not only can compensate for this defect of the flow graph model but also can analyze and debug the model well
$[11,20]$. Combined with the method of rate variable based in-tree model, this paper establish two-part diagram of rate variable based in-tree model of the village officials corruption in the field of precision poverty alleviation (see Figure 2).

Figure 2 means that (1) the changes of corruption convicted by village officials $R_{1(t)}$ are not only affected by the amount of corruption reported by people $\mathrm{L}_{2(\mathrm{t})}$ but also affected by the amount of corruptions investigated by government $\mathrm{L}_{3(\mathrm{t})}$ and the amount of corruption reported by media $\mathrm{L}_{4(\mathrm{t})}$; (2) the change of corruption reported by people $R_{2(t)}$ is affected by the amount of corruption convicted by village officials $\mathrm{L}_{1(\mathrm{t})}$; (3) the changes of corruption investigated by government $R_{3(t)}$ are affected by the amount of corruption convicted by village officials $\mathrm{L}_{1(\mathrm{t})}$; (4) the change of corruption reported by media $R_{4(t)}$ is not only affected by the amount of corruption convicted by village officials $\mathrm{L}_{1(\mathrm{t})}$ but also affected by the amount of corruption reported by people $\mathrm{L}_{2(\mathrm{t})}$ and the amount of corruption investigated by government $\mathrm{L}_{3(\mathrm{t})}$.

According to the order of fewer to more flow numbers, we established rate variable based in-tree model of village officials' corruption in the field of precision poverty alleviation [see formula (1)].

$$
\begin{aligned}
& R_{2(t)}=f_{1}\left(L_{1(t)}, a_{1}\right) \\
& R_{3(t)}=f_{2}\left(L_{1(t)}, a_{2}\right) \\
& R_{1(t)}=f_{3}\left(L_{2(t)}, L_{3(t)}, L_{4(t)}, a_{3}\right) \\
& R_{4(t)}=f_{4}\left(L_{1(t)}, L_{2(t)}, L_{3(t)}, a_{4}\right)
\end{aligned}
$$




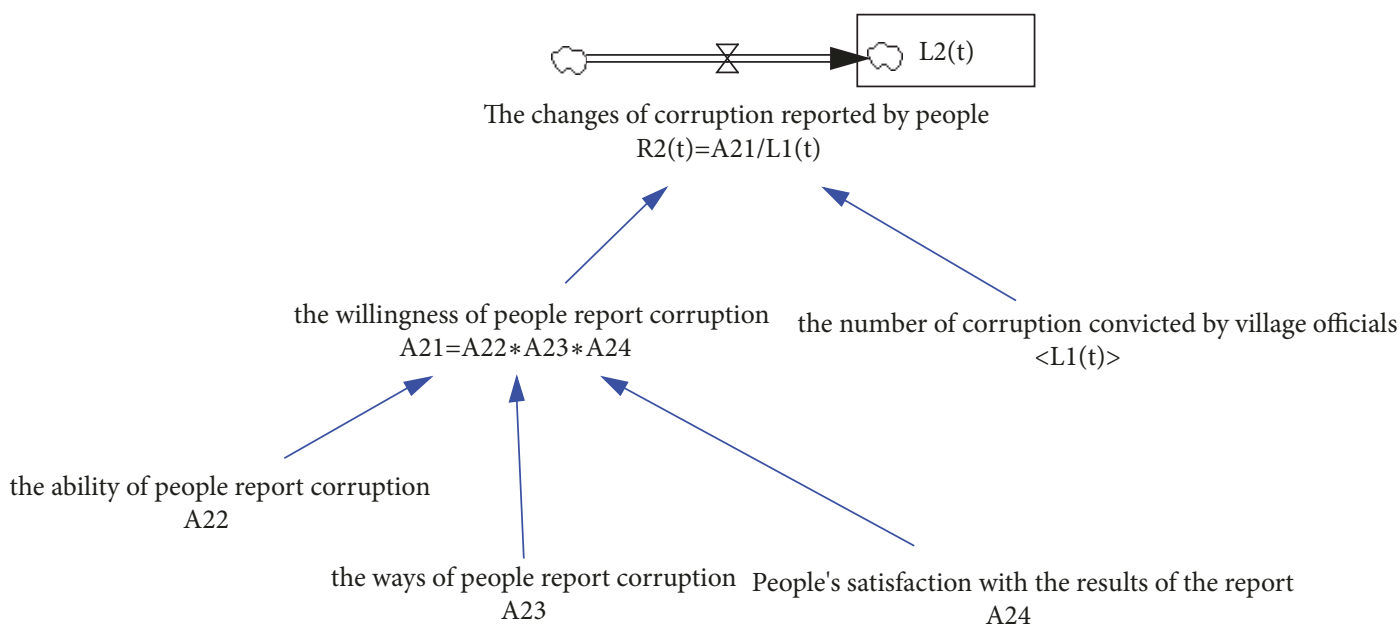

FIGURE 3: The equation of rate variable based in-tree according to the changes of corruption reported by people.

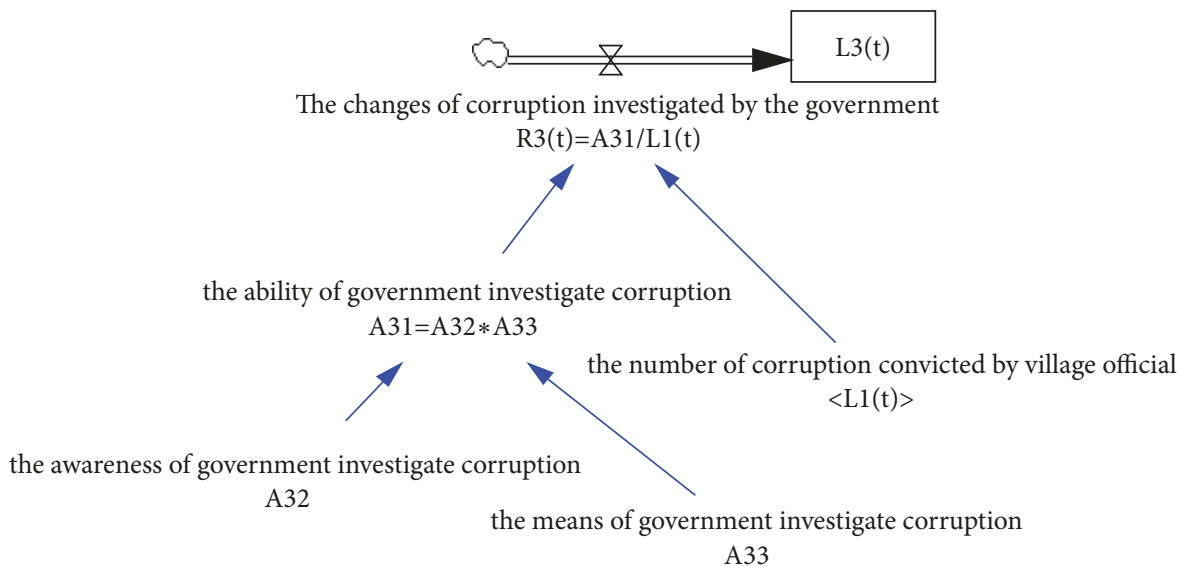

FIGURE 4: The equation of rate variable based in-tree according to the changes of corruption investigated by the government.

(1) Establishing rate variable based in-tree $T_{2(t)}$ according to the changes of corruption reported by people $R_{2(t)}$ (see Figure 3).

(1) The changes of corruption reported by people $R_{2(t)}=$ the willingness of people report corruption $\mathrm{A}_{21}$ /the number of corruption convicted by village officials $\mathrm{L}_{1(\mathrm{t})}$.

(2) The willingness of people report corruption $\mathrm{A}_{21}=$ the ability of people report corruption $\mathrm{A}_{22} *$ the ways of people report corruption $\mathrm{A}_{23} *$ People's satisfaction with the results of the report $\mathrm{A}_{24}$.

(2) Establishing rate variable based in-tree $T_{3(t)}$ according to the changes of corruption investigated by the government $R_{3(t)}$ (see Figure 4 ).

(1) The changes of corruption investigated by the government $R_{3(t)}=$ the ability of government investigate corruption $\mathrm{A}_{31} /$ the number of corruption convicted by village officials $\mathrm{L}_{1(\mathrm{t})}$.

(2) The ability of government investigate corruption $\mathrm{A}_{31}=$ the awareness of government investigate corruption $A_{32} *$ the means of government investigate corruption $\mathrm{A}_{33}$.
(3) Establishing rate variable based in-tree $T_{1(t)}$ according to the changes of corruption convicted by village officials $R_{1(t)}$ (see Figure 5).

(1) The changes of corruption convicted by village officials $R_{1(t)}=$ the willingness of village officials want to corrupt $A_{11}$ /(the number of corruption reported by people $\mathrm{L}_{2(\mathrm{t})}+$ the number of corruption investigated by government $\mathrm{L}_{3(\mathrm{t})}+$ the number of corruption reported by media $\left.\mathrm{L}_{4(\mathrm{t})}\right)$

(2) The willingness of village officials want to corrupt $A_{11}=$ official culture $A_{12} *$ institution loophole $A_{13} *$ official thoughts $\mathrm{A}_{14}$.

(4) Establishing rate variable based in-tree $T_{4(t)}$ according to the changes of corruption reported by media $R_{4(t)}$ (see Figure 6).

(1) The changes of corruption reported by media $R_{4(t)}=$ the willingness of media report corruption $\mathrm{A}_{41} /$ (the number of corruption convicted by village officials $\mathrm{L}_{1(\mathrm{t})}+$ the number of corruption reported by people $L_{2(t)}+$ the number of corruption investigated by government $\left.\mathrm{L}_{3(\mathrm{t})}\right)$. 


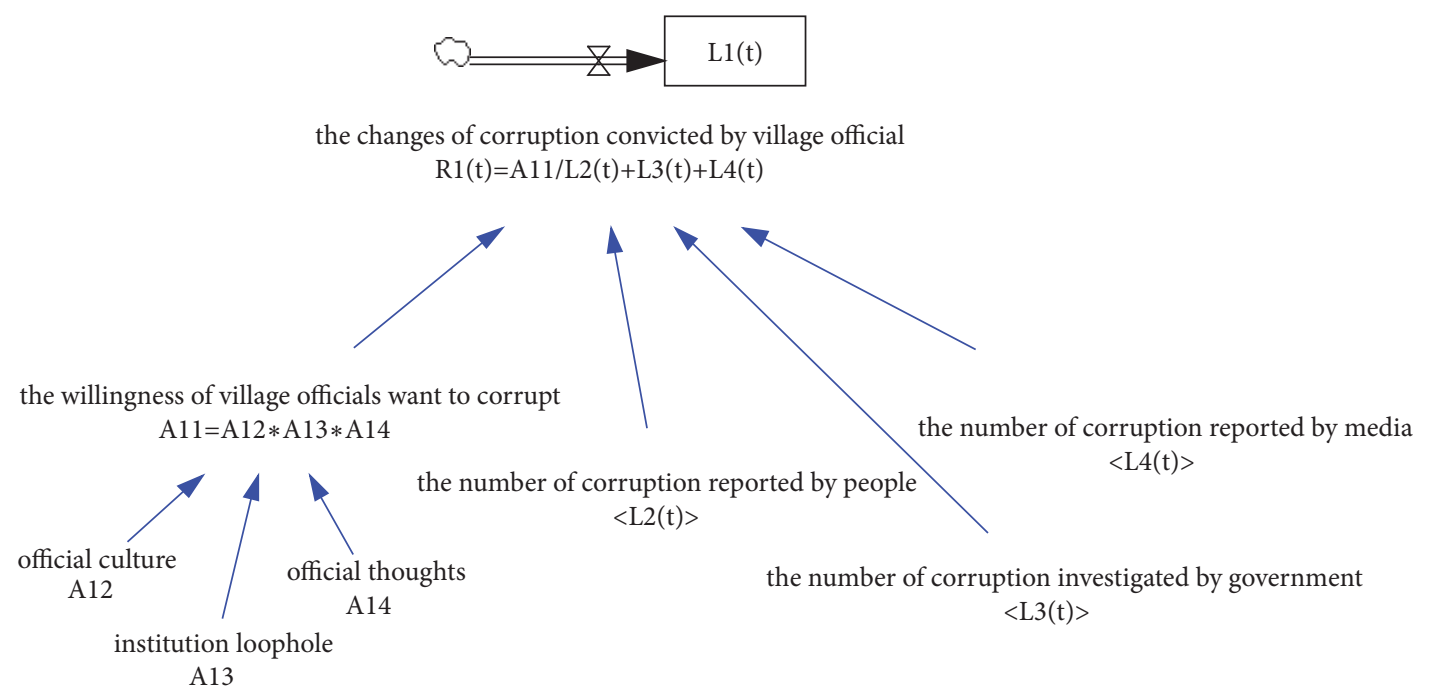

FIGURE 5: The equation of rate variable based in-tree according to the changes of corruption convicted by village officials.

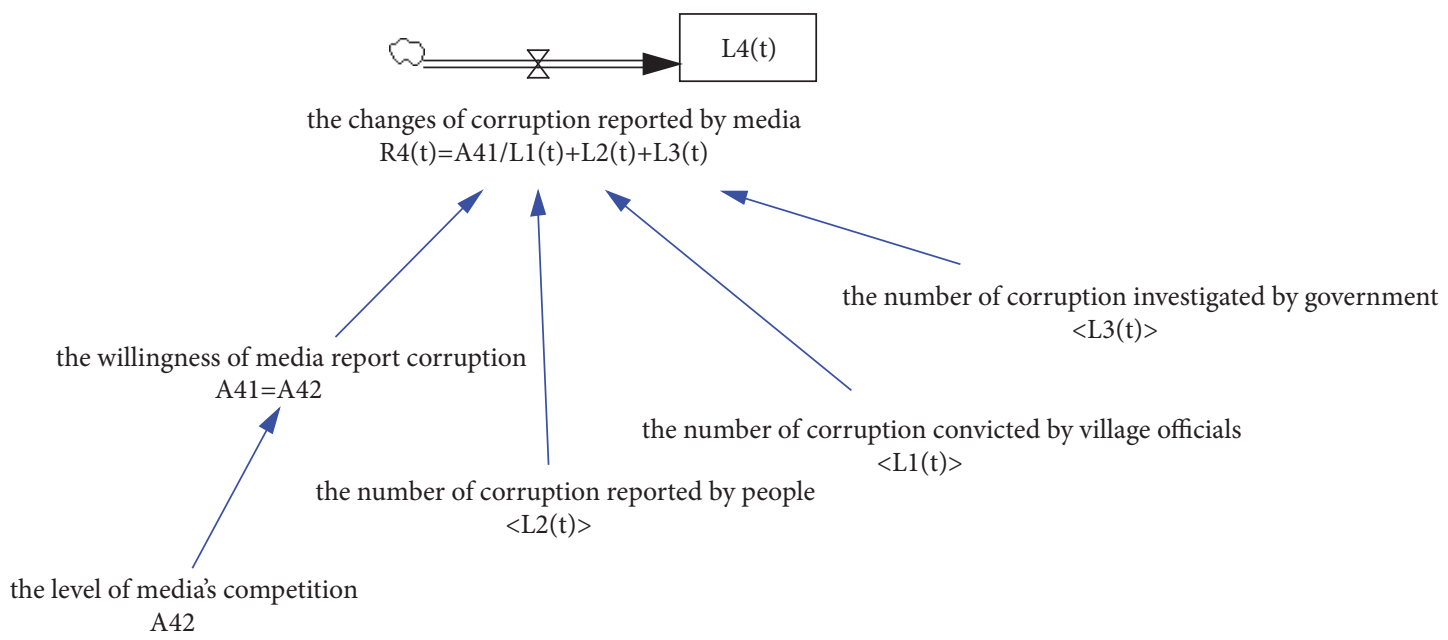

FIGURE 6: The equation of rate variable based in-tree according to the changes of corruption reported by media.

(2) The willingness of media report corruption $\mathrm{A}_{41}=$ the level of media's competition $\mathrm{A}_{42}$

According to the analysis above, a growth ceiling model and its equation for village officials' corruption in the field of precision poverty alleviation is generated [see Figure 7 and formula (2)].

$$
\begin{aligned}
& L_{1(t)}=L_{1(t 0)}+\frac{A_{12} * A_{13} * A_{14}}{\left[L_{2(t)}+L_{3(t)}+L_{4(t)}\right]} \\
& L_{2(t)}=L_{2(t 0)}+\frac{A_{22} * A_{23} * A_{24}}{L_{1(t)}} \\
& L_{3(t)}=L_{3(t 0)}+\frac{A_{32} * A_{33}}{L_{1(t)}} \\
& L_{4(t)}=L_{4(t 0)}+\frac{A_{42}}{\left[L_{1(t)}+L_{2(t)}+L_{3(t)}\right]}
\end{aligned}
$$

\section{Simulation Analysis}

4.1. Background [21]. During the two years from 2016 to 2017, Xiong $* *$, the Secretary and Director of the G.S. Residents Committee of the Z.X. Town F.C. City illegally collected 22,680 RMB from the low-income households for the street lamp installation project. At the end of 2015, Mo **, the secretary of P.X. Village, T.S. Town, F.C. City, brought the unqualified wife into the poverty relief target and received the poverty relief fund of $600 \mathrm{RMB}$. In 2014, Zhong **, the member of R.H. Village, T.C. Town of F.C. City, did not work carefully and brought the seven people who had already been out of poverty once again into the poor households. The three cases of "micro-corruption" are the typical case of corruption in the field of poverty alleviation which has experienced the occurrence of village officials' corruption, the report of people, the investigation of government, and the report of media. So this paper takes them as the research object. 


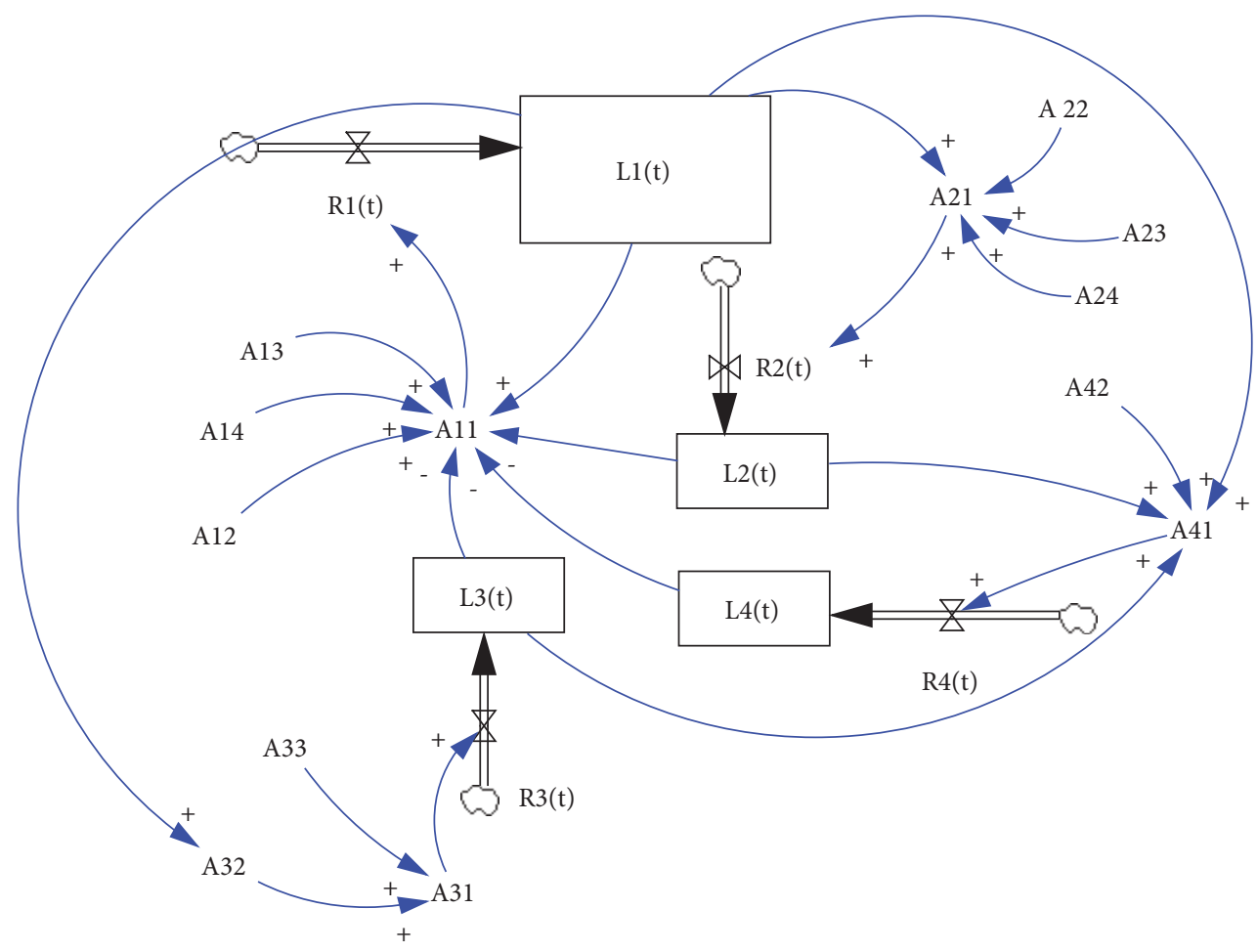

FIGURE 7: The growth ceiling model for village officials' corruption in the field of precision poverty alleviation.

TABLE 1: The weight matrix of four variables.

\begin{tabular}{lcccc}
\hline & A11 & A31 & A41 & A21 \\
A11 & 1.000 & 2.079 & 2.094 & 2.709 \\
A31 & 0.481 & 1.000 & 2.867 & 1.557 \\
A41 & 0.478 & 0.349 & 1.000 & 2.191 \\
A21 & 0.369 & 0.642 & 0.456 & 1.000 \\
\hline
\end{tabular}

\subsection{Source of Data}

Data Weight. Combining the three typical cases, the method of analytic hierarchy process (AHP) is used and experts and professors from the School of Public Administration of Nanchang University are invited to give scores for the four variables (the willingness of village officials to corrupt A11, the willingness of people to report corruption A21, the ability of government to investigate corruption A31, and the willingness of media report corruption A41) and obtained the weight matrix of Table 1.

According to Table 1, the weight of village officials' willingness to corrupt, people's willingness to report, government's ability to investigate and media's willingness to report are, respectively, $0.407,0.277,0.185$, and 0.131 . The characteristic root is 4.218 , the consistency index (C.I.) = $0.073<0.1$, and the average random consistency index (R.I.) $=0.081<0.1$. According to C.I. and R.I., it is judged that the above matrix conforms to a satisfactory consistency criterion and the corresponding weight vector $\mathrm{W}$ is acceptable. Then substitute these weights into the equation of rate variable based in-tree model.
Other Sources of Data. Combine with the three typical cases, interview the grassroots staff and issue questionnaires in a targeted manner, assign values to the options, and obtain the data in Table 2 after weighted average. The value of each variable is substituted into the equation of rate variable based in-tree model.

\subsection{Simulation Analysis}

The Simulation Result of the System. The model was simulated by the software of Vensim PLE and it was found that the village officials' willingness to corrupt has the most significant impact on the number of village officials' corruption. On the basis of the initial value, while the variables affecting the number of village officials' corruption (the village officials' willingness to corrupt, the people's willingness to report corruption, the government's ability to investigate corruption, and the media's willingness to report corruption) increased by $25 \%$, the willingness of village officials' corruption to the number of village officials' corruption is particularly significant (see Figure 8). 
TABLE 2: The value of other variable.

\begin{tabular}{llll}
\hline A32 & 0.74 & A24 & 0.54 \\
A33 & 0.71 & A12 & 0.54 \\
A42 & 0.65 & A13 & 0.72 \\
A22 & 0.48 & A14 & 0.56 \\
A23 & 0.58 & & \\
\hline
\end{tabular}

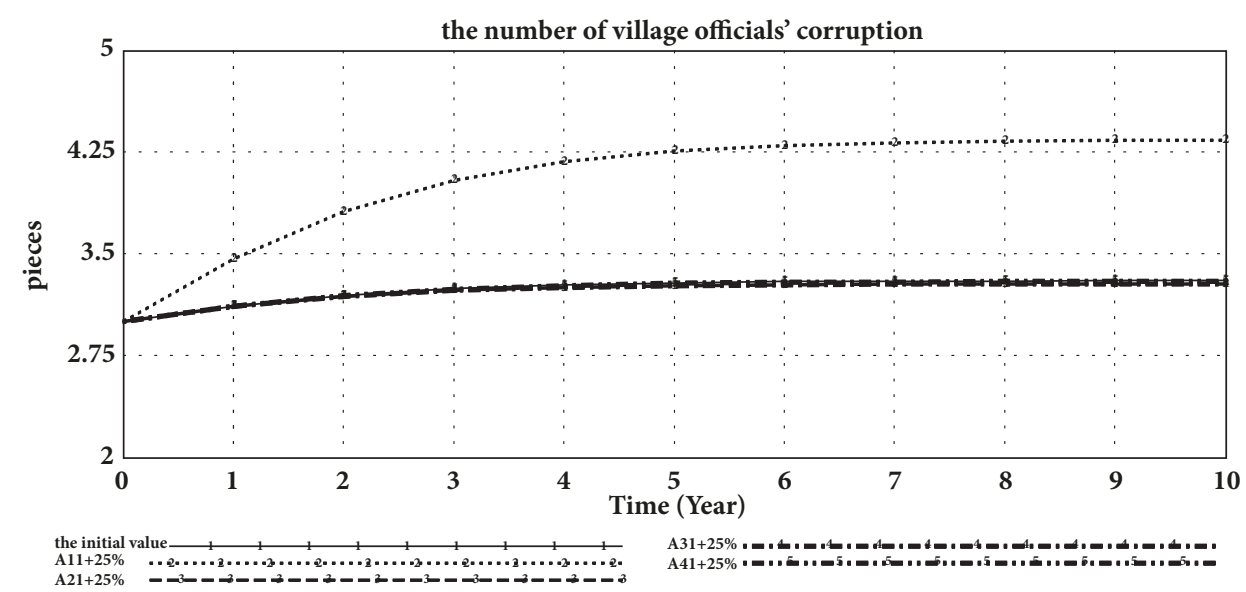

FIGURE 8: The affection of four variables on the number of village officials' corruption.

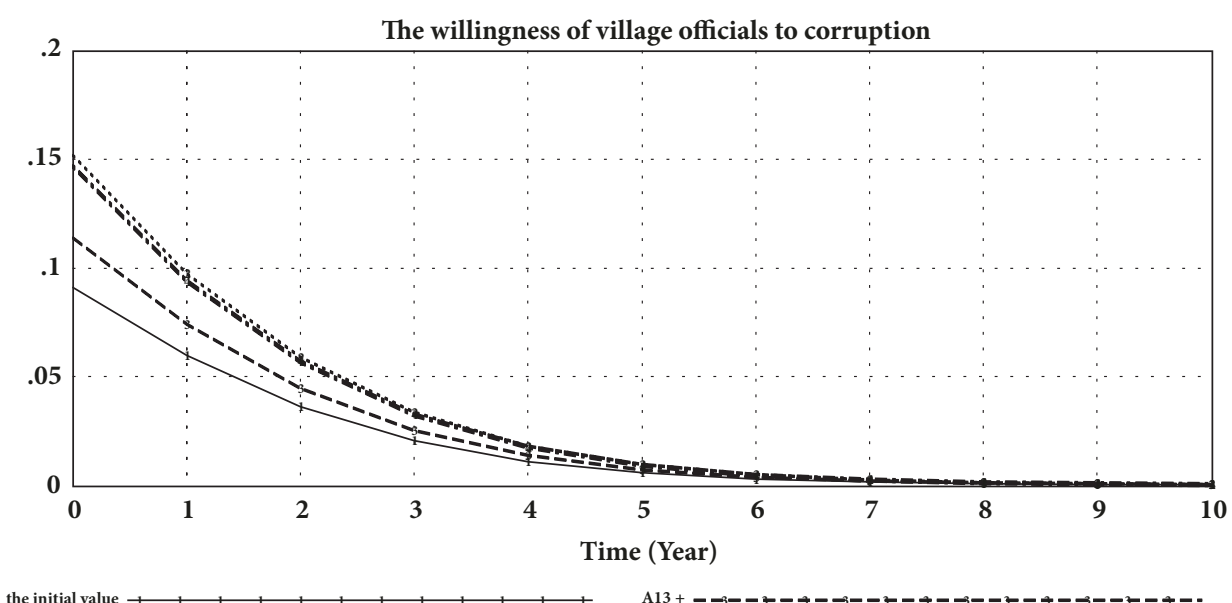

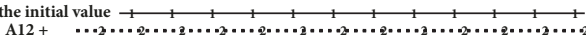

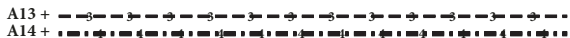

FIGURE 9: The affection of three variables on the willingness of village officials' corruption.

The Simulation Result of Village Officials' Subsystem. We found that the official culture has the greatest influence on the village officials' willingness to corrupt, followed by the village officials' thoughts, and the system to prevent corruption. The simulation results show that on the basis of the initial value, the three factors that affecting the village officials' willingness to corrupt are increased by $25 \%$, and curve 2, curve 3, and curve 4 in Figure 9 are obtained. Compared with the initial value curve 1, official culture has the greatest influence on the willingness of the village officials to corrupt, and then the village officials' thoughts and the system to prevent corruption. The simulation results are in line with reality. Under President Xi Jinping's high-pressure anticorruption system, the official culture has been greatly improved and the village officials' willingness to corrupt has dropped significantly.

The Simulation Result of People Subsystem. We found that the important factors that influence the willingness of people's report are respectively: the ability of people to report, the satisfaction of people with the report results, and the way people to report. The simulation results show that, on the basis of the initial value, the variables affecting the willingness of people to report corruption are, respectively, increased by $25 \%$, and curve 2 , curve 3 , and curve 4 in Figure 10 are obtained. Compared with the initial value curve 1 , people's reporting ability has the greatest impact on the people's willingness to report corruption, and then 


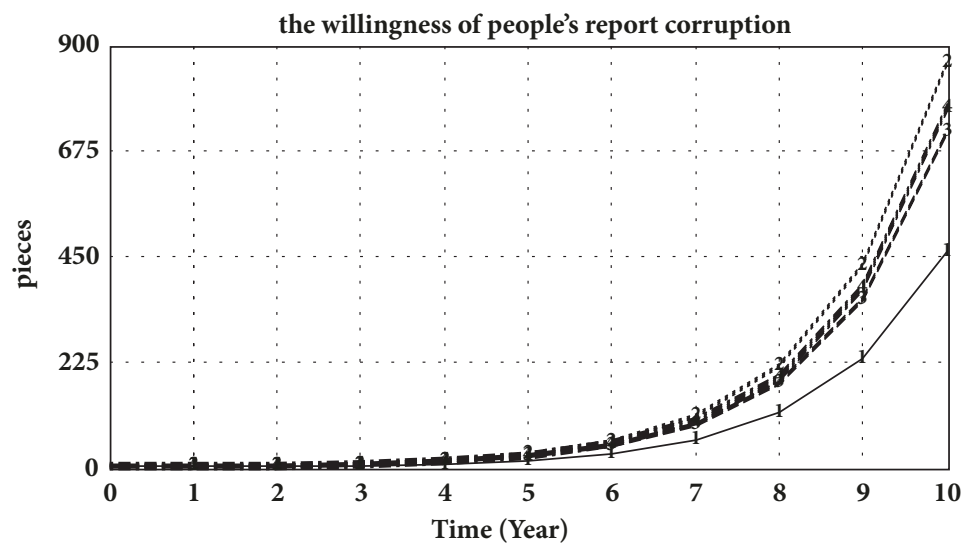

the initial value $\begin{array}{llll}1 & 1 & 1\end{array}$

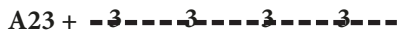

$\mathrm{A} 22+\ldots \ldots 2 \ldots \ldots 2 \ldots \ldots 2 \ldots \ldots 2 \ldots$

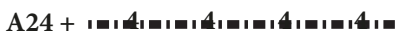

FIGURE 10: The affection of three variables on the willingness of people report corruption.

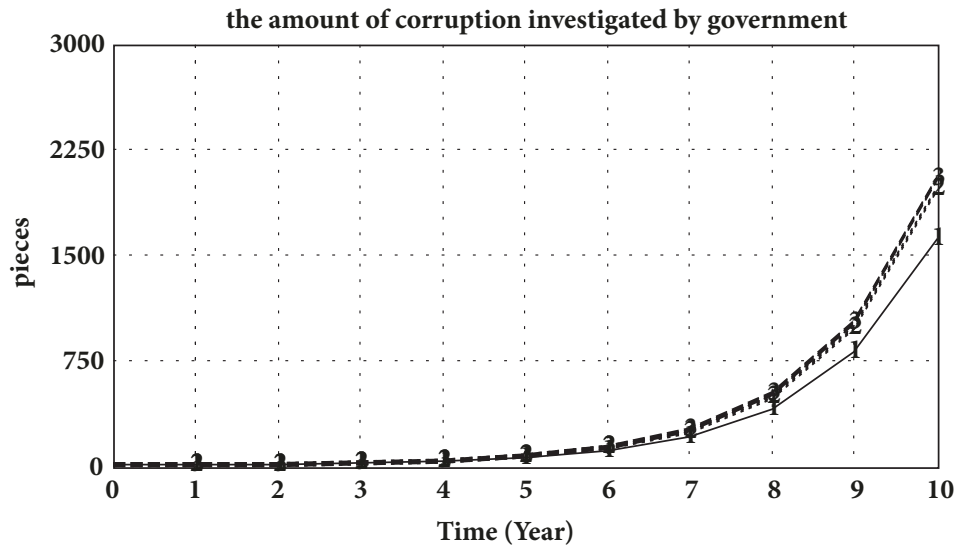

the initial value $\begin{array}{ccccc}1 & 1 & 1 & 1\end{array}$

$\mathrm{A} 33+---3---3--3--2---3-$

FIGURE 11: The affection of two variables on the amount of corruption investigated by government.

people's satisfaction with the report results, people's reporting methods.

The Simulation Result of Government Subsystem. We found that the awareness of government investigates corruption and the ability to investigate corruption is equally important for the amount of corruption investigated by government. The simulation results show that, on the basis of the initial value, the awareness and ability of government's investigation corruption are, respectively, increased by $25 \%$, and curve 2 and curve 3 in Figure 11 are obtained. Compared with the initial value curve 1 , the awareness and the ability of government investigate corruption are equally important to the amount of corruption investigated by government.

Sensitivity Testing. In the village officials' subsystem, the official culture, village officials' thought, and prevention system affecting village officials' corruption are, respectively, increased by $25 \%$ and reduced by $25 \%$, and curve 2 and curve 3 are obtained. Compared with the initial value simulation curve 1 , the simulation results show that the variables pass sensitivity test. In the same way, the variables in the subsystems of people, government, and media are, respectively, increased by $25 \%$ and reduced by $25 \%$ based on the initial values and, compared with the initial value curve 1 , the simulation results show that these variables pass the sensitivity test (See Figures 12(a)-12(d)).

\section{Conclusion}

This paper uses one of the methods of system dynamics (rate variable based in-tree model) to qualitative analysis the factors affecting the corruption of village officials in the field of precision poverty alleviation and the interaction mechanism between the various. The simulation analysis was carried out in combination with typical cases and survey data in the field of precision poverty alleviation. The study 

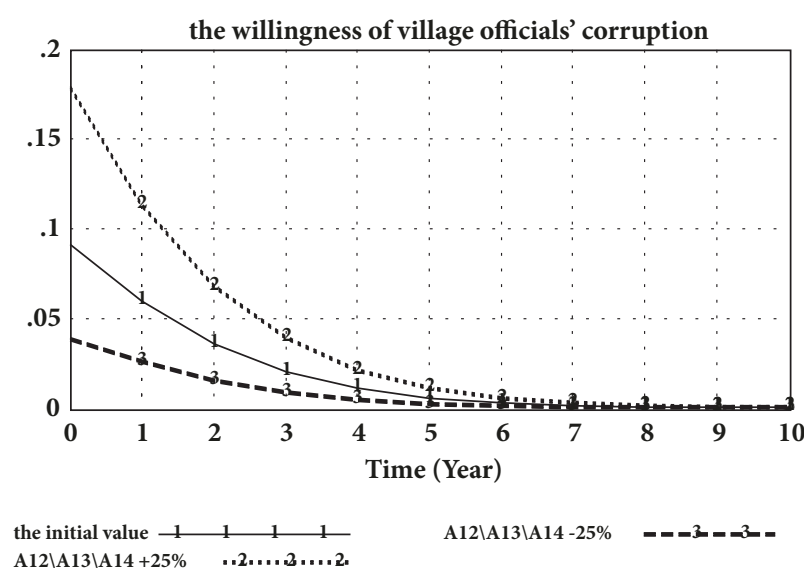

(a)

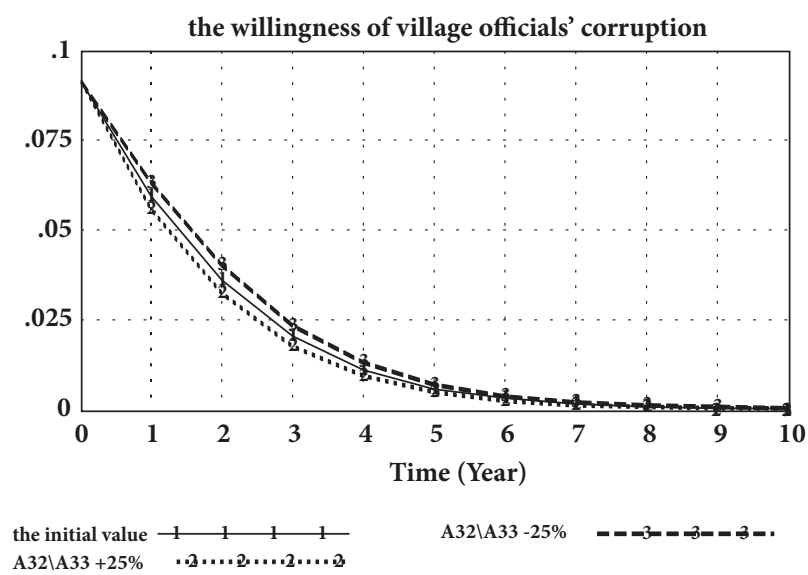

(c)

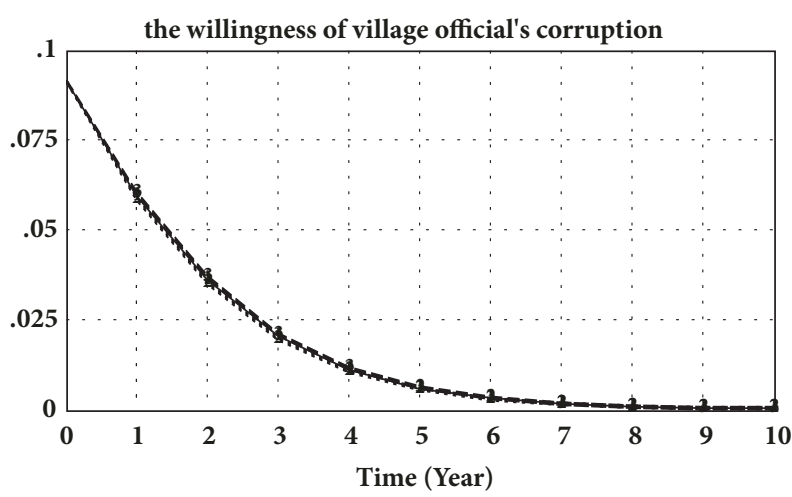

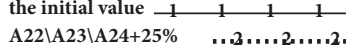

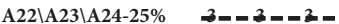

(b)

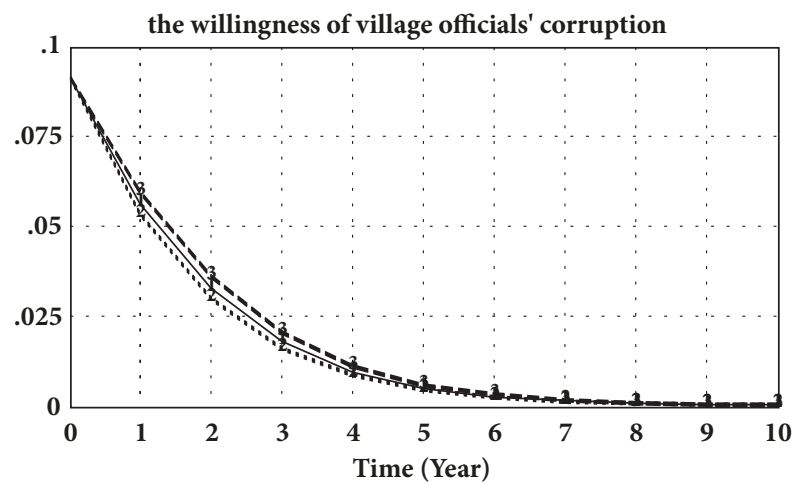

the initial value $\begin{array}{llll}1 & 1 & 1 & 1 \\ \mathrm{~A} 42+25 \% & . .2 \ldots .2 \ldots 2 \ldots 2 \ldots 2 \ldots 2\end{array}$

A42-25\%

(d)

Figure 12

found that, among the four factors that affect village officials' corruption, the influence of village officials' willingness to corrupt on the number of village officials' corruption is crucial. Further research found that the influence of official culture, village officials' thought, and prevention system on the corrupt will of village officials in a decreasing relationship. The study also found that, in the subsystem of people, the degree of influence on the number of village officials' corruption is the ability of people to report corruption, the satisfaction with the report results, and the way to report. In the government subsystem, the awareness and the ability of government investigate corruption are equally important to the village officials' willingness to corrupt.

\section{Data Availability}

The data used to support the findings of this study are available from the corresponding author upon request.

\section{Conflicts of Interest}

The authors declare no conflicts of interest.

\section{Acknowledgments}

This work was supported by the National Social Science Fund of China (under Grant no. 16BZZ011).

\section{References}

[1] http://www.xinhuanet.com/photo/2018-02/14/c_ 1122419727.htm.

[2] http://www.moa.gov.cn/ztzl/yhwj/zyyhwj/.

[3] L. H. He, "Identification of poor population under the background of accurate poverty alleviation: theory, practice and policy," Journal of South-Central University for Nationalities (Humanities and Social Sciences), vol. 02, pp. 140-144, 2017.

[4] X. p. Shen, "Inducement and prevention mechanism of, village official, corruption in the field of precision poverty alleviation--based on the typical case of 168 cases in 6 provinces in central China," Ningxia Social Sciences, vol. 11, pp. 41-44, 2017.

[5] H. b. Ma, "Research on the main problems and countermeasures of poverty alleviation in rural areas in China," Agricultural Economy, vol. 01, pp. 12-14, 2017. 
[6] J. P. Chen, W. W. Hu, and Y. F. Zheng, "Research on the mechanism and governance path of small-scale power corruption in rural grassroots," Henan Social Sciences, vol. 05, pp. 25-31, 2016.

[7] G. Mo, "Precise anti-corruption: political ecological protection for poverty alleviation--a series of researches on precision poverty alleviation performance improvement mechanism," Administration Forum, vol. 01, pp. 40-46, 2017.

[8] C. Wang, "On the construction of the mechanism of punishment and prevention of duty crimes--taking the punishment of duty crimes in the poverty alleviation as an example," Journal of Chongqing University (Social Science Edition), vol. 01, pp. 123136, 2018.

[9] W. F. Jay, Principles of Systems, Tsinghua University Press, 1986, Translated by H. B. Wang.

[10] Q. P. Wang, System Dynamics Review, Tsinghua University Press, 1985.

[11] R. A. Jia and R. H. Ding, Complex Dynamic Analysis of System Dynamics Feedback, Higher Education Press, 2002.

[12] X. Xu, Y. Li, X. Liu, and W. Gan, "Does religion matter to corruption? Evidence from China," China Economic Review, vol. 42, pp. 34-49, 2017.

[13] H. T. Kim, M. Papanastassiou, and Q. Nguyen, "Multinationals and the impact of corruption on financial derivatives use and firm value: Evidence from East Asia," Journal of Multinational Financial Management, vol. 39, pp. 39-59, 2017.

[14] G. Kotera, K. Okada, and S. Samreth, "Government size, democracy, and corruption: An empirical investigation," Economic Modelling, vol. 29, no. 6, pp. 2340-2348, 2012.

[15] A. De Chiara and L. Livio, "The threat of corruption and the optimal supervisory task," Journal of Economic Behavior \& Organization, vol. 133, pp. 172-186, 2017.

[16] Z. Yan, "Big data and government governance," in Proceedings of the 2018 International Conference on Information Management and Processing (ICIMP), pp. 111-114, London, January 2018.

[17] A. Brunetti and B. Weder, "A free press is bad news for corruption," Journal of Public Economics, vol. 87, no. 7-8, pp. 1801-1824, 2003.

[18] N. Dutta and S. Roy, "The interactive impact of press freedom and media reach on corruption," Economic Modelling, vol. 58, pp. 227-236, 2016.

[19] D. Schultz and K. Harutyunyan, "Combating corruption: The development of whistleblowing laws in the United States, Europe, and Armenia," International Comparative Jurisprudence, vol. 1, no. 2, pp. 87-97, 2015.

[20] B. B. Leng, "Construction and application of system dynamics evolutionary game rate variable based in-tree model--Basing on feedback simulation of scale pig breeding ecological energy system stability," in Systems Engineering Theory \& Practice, pp. 1360-1372, 2017.

[21] http://www.ycjjjc.gov.cn/pgt//_548617.html. 


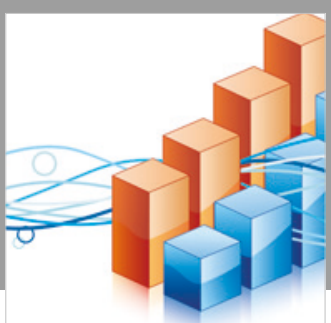

Advances in

Operations Research

\section{-n-m}
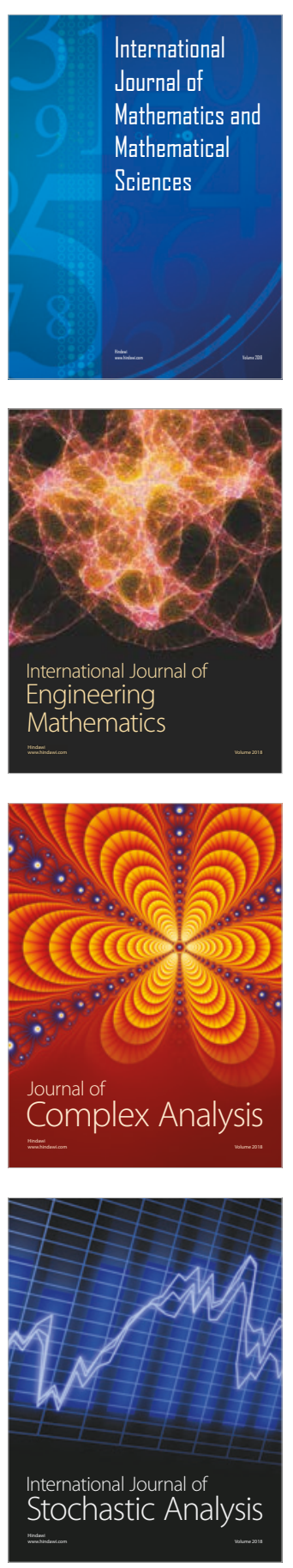
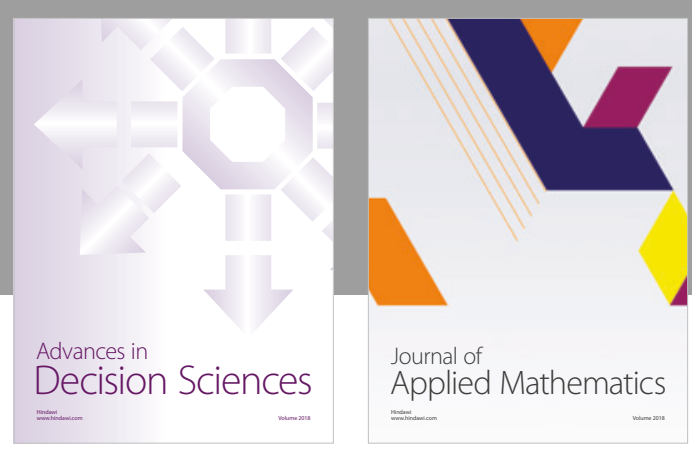

Journal of

Applied Mathematics
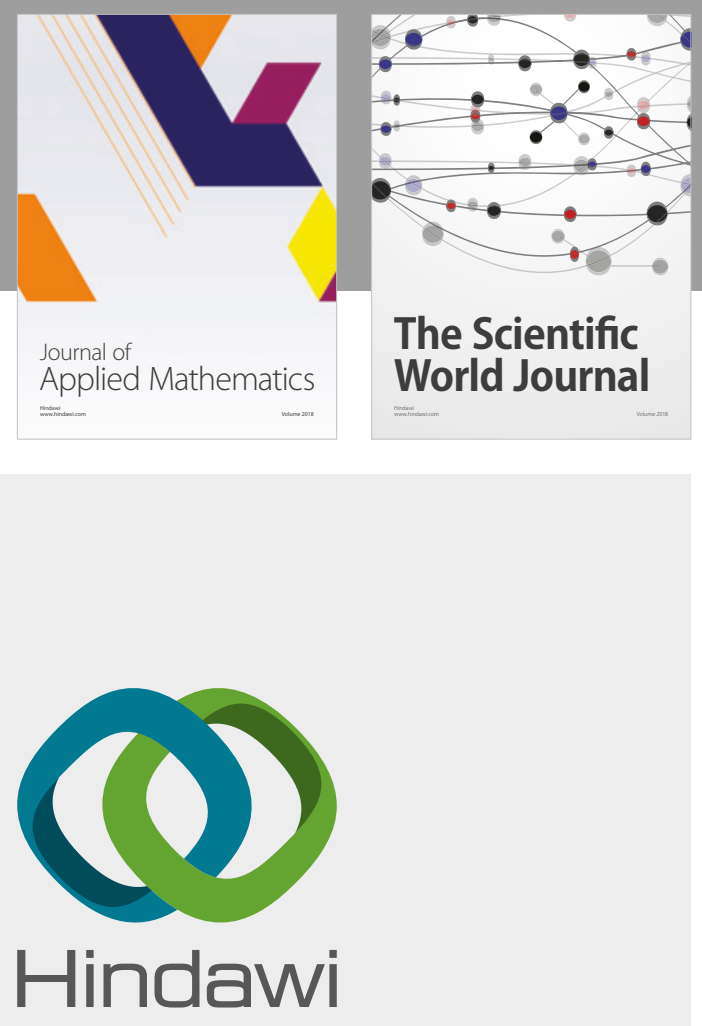

Submit your manuscripts at

www.hindawi.com

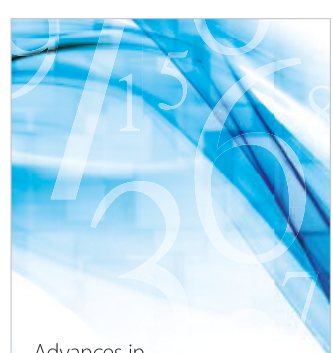

Advances in
Numerical Analysis
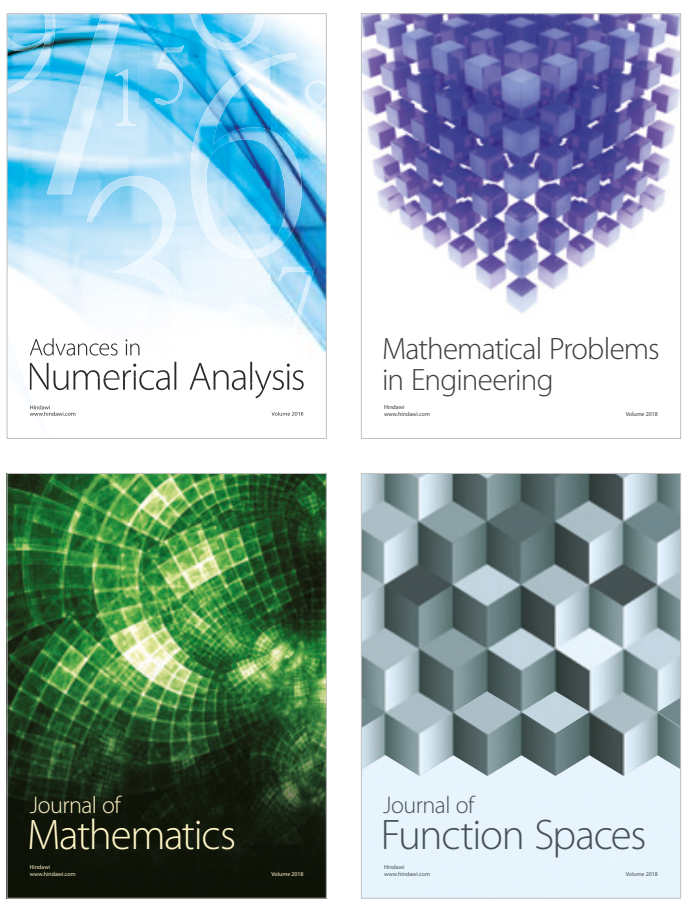

Mathematical Problems in Engineering

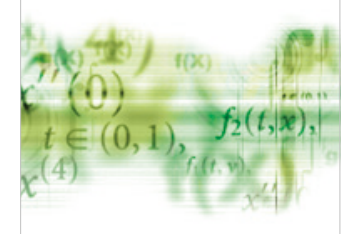

International Journal of

Differential Equations

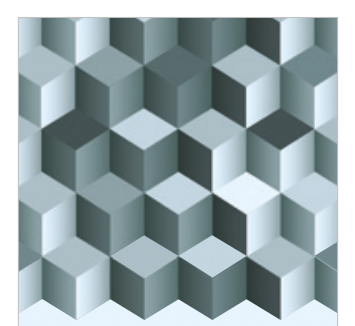

Journal of

Function Spaces
The Scientific

World Journal

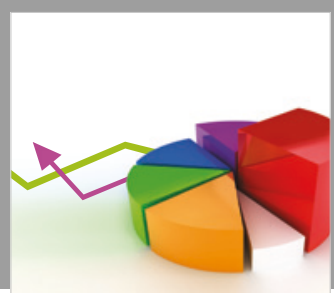

Journal of

Probability and Statistics
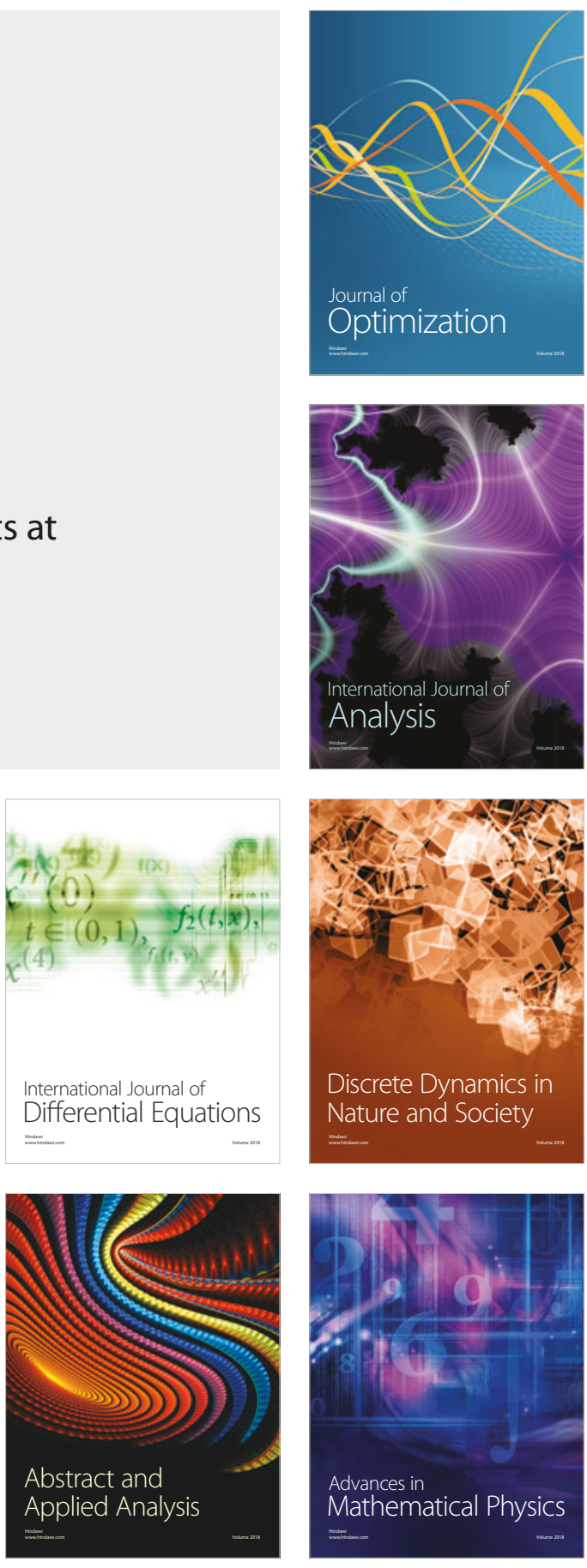